\title{
Oral antiplatelet therapy for atherothrombotic disease: overview of current and emerging treatment options
}

This article was published in the following Dove Press journal:

Vascular Health and Risk Management

I4 February 2012

Number of times this article has been viewed

\section{Dan J Fintel}

Bluhm Cardiovascular Institute, Feinberg School of Medicine, Northwestern University, Chicago, IL, USA
Correspondence: Dan J Fintel Bluhm Cardiovascular Institute, Feinberg School of Medicine, Northwestern University, Chicago, IL 606 I I, USA

Tel +I (3I2) 6952745

Fax +I (3I2) 6950066

Email dfintel@northwestern.edu
Abstract: Clinical presentations of atherothrombotic vascular disease, such as acute coronary syndromes, ischemic stroke or transient ischemic attack, and symptomatic peripheral arterial disease, are major causes of morbidity and mortality worldwide. Platelet activation and aggregation play a seminal role in the arterial thrombus formation that precipitates acute manifestations of atherothrombotic disease. As a result, antiplatelet therapy has become the cornerstone of therapy for the prevention and treatment of atherothrombotic disease. Dual antiplatelet therapy with aspirin and a $\mathrm{P} 2 \mathrm{Y}_{12}$ adenosine diphosphate (ADP) receptor inhibitor, such as clopidogrel or prasugrel, is the current standard-of-care antiplatelet therapy in patients with acute coronary syndromes managed with an early invasive strategy. However, these agents are associated with several important clinical limitations, including significant residual risk for ischemic events, bleeding risk, and variability in the degree of platelet inhibition. The residual risk can be attributed to the fact that aspirin and $\mathrm{P} 2 \mathrm{Y}_{12}$ inhibitors block only the thromboxane $\mathrm{A}_{2}$ and ADP platelet activation pathways but do not affect the other pathways that lead to thrombosis, such as the protease-activated receptor-1 pathway stimulated by thrombin, the most potent platelet agonist. Bleeding risk associated with aspirin and $\mathrm{P} 2 \mathrm{Y}_{12}$ inhibitors can be explained by their inhibitory effects on the thromboxane $\mathrm{A}_{2}$ and ADP pathways, which are critical for protective hemostasis. Interpatient variability in the degree of platelet inhibition in response to antiplatelet therapy may have a genetic component and contribute to poor clinical outcomes. These considerations underscore the clinical need for therapies with a novel mechanism of action that may reduce ischemic events without increasing the bleeding risk.

Keywords: acute coronary syndromes, antiplatelet therapy, ADP, thromboxane $\mathrm{A}_{2}$, PAR-1, bleeding

\section{Introduction}

Platelets play a key role in preventing blood loss in response to injury, but they are also critical for the formation of pathogenic thrombi responsible for the acute clinical manifestations of atherothrombotic disease. These events include acute coronary syndromes (ACS: unstable angina [UA], non-ST-elevation [NSTE] myocardial infarction [MI], and ST-elevation MI [STEMI]), ischemic stroke/transient ischemic attack (TIA), and symptomatic peripheral artery disease (PAD), which are major causes of morbidity and mortality worldwide. ${ }^{1,2}$

The crucial step in both protective hemostasis and pathological thrombosis is platelet activation, which can occur via multiple pathways. These pathways are activated by binding of specific agonists, such as thromboxane $\mathrm{A}_{2}\left(\mathrm{TxA}_{2}\right)$, adenosine diphosphate (ADP), and thrombin, to their corresponding receptors on the platelet surface..$^{3-5}$ 
Additional factors that contribute to platelet activation include epinephrine, prostaglandin $\mathrm{E}_{2}$, serotonin, and various chemokines. Although these factors may directly activate platelets, this effect is very weak, and they predominantly serve to potentiate platelet activation induced by other stimuli. ${ }^{5}$ Under physiological conditions, ligand-stimulated activation of platelets is counteracted by a number of endothelial-derived factors that prevent uncontrolled platelet aggregation, including nitric oxide and prostacyclin, which raise the intracellular levels of cyclic nucleotides (cyclic guanosine monophosphate and cyclic adenosine monophosphate). In addition, the nucleoside adenosine, which is released as a result of cell damage or by endothelial ectonucleotidase CD39-mediated conversion of ADP, also inhibits platelet activation via activation of the $\mathrm{G}^{\mathrm{s}}$-coupled adenosine $\mathrm{A}_{2 \mathrm{~A}}$ receptor. ${ }^{5,6}$

Current oral antiplatelet agents target the $\mathrm{TxA}_{2}$ (aspirin) and ADP (P2 $\mathrm{Y}_{12}$ inhibitors, such as clopidogrel, ticlopidine, and prasugrel) platelet activation pathways ${ }^{4}$ and have been demonstrated to significantly reduce the incidence of ischemic events in patients with atherothrombotic disease. ${ }^{7-10}$ The well-documented efficacy of aspirin and clopidogrel has been recognized by the American College of Cardiology/American Heart Association guidelines, ${ }^{11-14}$ and dual antiplatelet therapy with aspirin and a $\mathrm{P} 2 \mathrm{Y}_{12}$ inhibitor has emerged as the standard of care in the management of patients with ACS.

However, despite the established benefits of aspirin and ADP receptor inhibitors, these agents are associated with important clinical limitations, including a high residual risk for ischemic events, elevated bleeding risk, and variable inhibition of platelet aggregation. These considerations underscore the need for novel therapies that can further reduce the risk for ischemic events without exposing patients to increased risk of bleeding. The aims of this review are to provide a pathophysiological rationale for the clinical use of antiplatelet agents, to summarize the benefits and limitations of current oral antiplatelet therapies, and to discuss novel approaches to oral antiplatelet therapy.

\section{Pathogenesis of atherothrombosis and rationale for antiplatelet therapy}

Atherosclerosis develops within the intima of large- and medium-sized arteries and can be triggered by behavioral, environmental, biochemical, or genetic factors. ${ }^{15}$ The earliest pathological feature of atherothrombosis is endothelial dysfunction, ${ }^{15-18}$ which is exemplified by endothelial cell expression of vascular cell adhesion molecules and increased endothelial permeability to lipoproteins, leukocytes, and other inflammatory mediators, favoring plaque growth. ${ }^{15,17,19}$ The composition of plaques is the major determinant of their susceptibility to rupture/erosion, which ultimately serves as a trigger that precipitates an acute thrombotic event. ${ }^{17,20}$ The unstable, rupture-prone lesions typically comprise a large core of extracellular lipid, a dense accumulation of macrophages, reduced numbers of vascular smooth muscle cells, and a thin, fibrous cap. Plaque rupture usually occurs in the areas where the cap is the thinnest and most heavily infiltrated with inflammatory cells. ${ }^{17,21}$ Rupture or erosion of these lesions exposes circulating blood to a highly thrombogenic environment that causes inappropriate platelet activation, ultimately leading to occlusion of the arterial lumen by platelet-rich thrombi. These thrombi obstruct blood flow and oxygen supply (ischemia) in the affected arteries and are responsible for the clinical manifestations of atherothrombotic diseases. ${ }^{15}$

Platelets play a critical role in atherothrombotic disease, as they are the primary constituent of occlusive thrombi at the sites of ruptured/eroded plaques. Formation of an occlusive thrombus proceeds in three stages: (1) the initiation phase, (2) the extension phase, and (3) the perpetuation phase. ${ }^{3-6,22}$ In the initiation phase, platelets roll, adhere, and spread on the subendothelial collagen matrix to form a platelet monolayer. The initial adhesion of platelets to subendothelium is mediated primarily by direct interaction between the glycoprotein (GP) Ib/V/IX receptor complex on the platelet surface and von Willebrand factor. Independent and direct interaction between exposed subendothelial collagen with platelet receptors GP VI and GP Ia stimulates the release of platelet agonists ADP and TxA from the adherent platelets, as well as activation of GP IIb/IIIa, the high-affinity fibrinogen receptor that mediates firm and stable adhesion of platelets to the vessel wall, platelet-platelet crosslinking, and contact-dependent signalling within platelet aggregates. ${ }^{3,5,6,22}$

Platelet activation in the extension phase is crucial for both hemostasis and thrombosis and can be induced by multiple agonists, including ADP, TxA 2 , and thrombin. ${ }^{6}$ Local release of ADP and $\mathrm{TxA}_{2}$ stimulated by collagen promotes the recruitment of circulating platelets into the growing, stable hemostatic plug. Thrombin-mediated cleavage of fibrinogen into fibrin can also contribute to the formation of hemostatic plugs. ADP and $\mathrm{TxA}_{2}$ activate platelets via binding to distinct receptors on the platelet surface (ADP binds to $\mathrm{P} 2 \mathrm{Y}_{1}$ and $\mathrm{P} 2 \mathrm{Y}_{12}$ receptors, and $\mathrm{TxA}_{2}$ binds the endoperoxide PGG2-PGH2 [TP] receptors $\mathrm{TP}_{\alpha}$ and $\mathrm{TP}_{\beta}$ ). ${ }^{3}$ ADP- and $\mathrm{TxA}_{2}$-induced activation of their corresponding 
receptors results in reduced intracellular cyclic adenosine monophosphate levels and full activation of GP IIb/IIIa. ${ }^{5}$ $\mathrm{ADP}$ and $\mathrm{TxA}_{2}$ can also potentiate platelet activation induced by other ligands. ${ }^{5}$ Thrombin activates platelets primarily by binding protease-activated receptor (PAR)-1 on the human platelet surface, cleaving the receptor, and exposing a tethered ligand, which binds and activates the receptor (Figure 1A). ${ }^{3,23,24}$ Thrombin is the most potent platelet agonist, as it can stimulate platelet activation via the PAR-1 pathway at very low concentrations (Figure 1B) that are several orders of magnitude lower than those required for the activation of the coagulation cascade. ${ }^{25,26}$ Human platelets also express a secondary receptor for thrombin, PAR-4, which requires higher concentrations of thrombin for activation than does PAR-1. ${ }^{23}$

The perpetuation phase of thrombus formation is mediated by the cell-to-cell contact-dependent mechanisms that lead to changes in platelet morphology, expression of procoagulant and proinflammatory molecules, and platelet aggregation. Thrombus in acute atherothrombotic events (ACS, ischemic stroke, or symptomatic PAD) can be either partially or completely occlusive - the former composed primarily of platelet aggregates, and the latter composed of a platelet aggregate core and a superimposed fibrin-rich clot generated by the coagulation cascade.

Platelets are therefore a critical mediator of thrombosis and acute ischemic events, but they are also essential for normal hemostasis. Because the activation of multiple platelet activation pathways is the primary mechanism of thrombosis and ischemic events, their comprehensive inhibition represents an attractive therapeutic approach in atherothrombotic disease. However, the potential clinical benefits of targeting various platelet activation pathways should be carefully weighed against the likelihood of increased bleeding, as both the $\mathrm{TxA}_{2}$ and ADP platelet activation pathways are also required for hemostasis.

\section{Overview of oral antiplatelet therapy}

The current standard-of-care oral antiplatelet therapy for patients with ACS (UA, NSTEMI, and STEMI) and following placement of a stent is the combination of aspirin and the thienopyridine $\mathrm{P} 2 \mathrm{Y}_{12}$ inhibitor clopidogrel or prasugrel, which is recommended for up to 1 year. ${ }^{11,12,14}$ Prasugrel is a novel oral thienopyridine $\mathrm{P}_{2} \mathrm{Y}_{12}$ inhibitor that has recently been approved in Europe and the US. The results of large clinical trials with high-dose clopidogrel and a novel, oral nonthienopyridine $\mathrm{P}_{12} \mathrm{Y}_{12}$ inhibitor ticagrelor (AZD6140) have been recently reported.

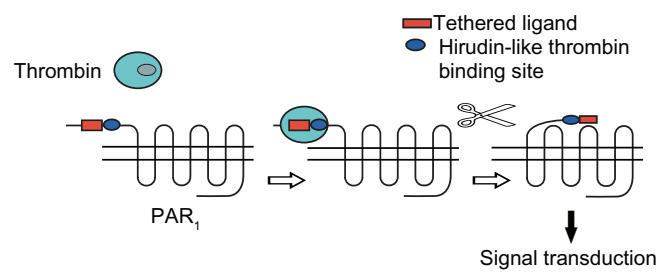

Figure IA Mechanism of protease-activated receptor (PAR)-I activation by thrombin. PAR-I is a G protein-coupled receptor for thrombin. Thrombin recognizes the $\mathrm{N}$-terminal exodomain of PAR-I by interacting with a hirudin-like domain. Thrombin cleaves the peptide bond between receptor residues arginine $4 I$ and serine 42 . This serves to unmask a new amino terminus that functions as a tethered ligand, which binds intramolecularly with the body of the receptor to effect transmembrane signalling. Reproduced with permission. Copyright (c) 2004. American Physiological Society. Ossovskaya VS, Bunnett NW. Protease-activated receptors: contribution to physiology and disease. Physiol Rev. 2004;84(2):579-621.24

\section{Aspirin}

Aspirin irreversibly inhibits cyclooxygenase-1 (COX-1), reducing the synthesis of $\mathrm{TxA}_{2}$, an important platelet activator. ${ }^{27}$ Numerous trials have documented the benefits of aspirin in patients with $\mathrm{ACS}^{8,28}$ and in those undergoing percutaneous coronary intervention (PCI), ${ }^{29,30}$ as well as in secondary prevention. ${ }^{8}$ A study of 1266 men with UA showed that daily aspirin significantly decreased the risk of death or $\mathrm{MI} ;{ }^{28}$ in other studies, pretreatment or long-term therapy with aspirin was shown to reduce the risk of thrombotic

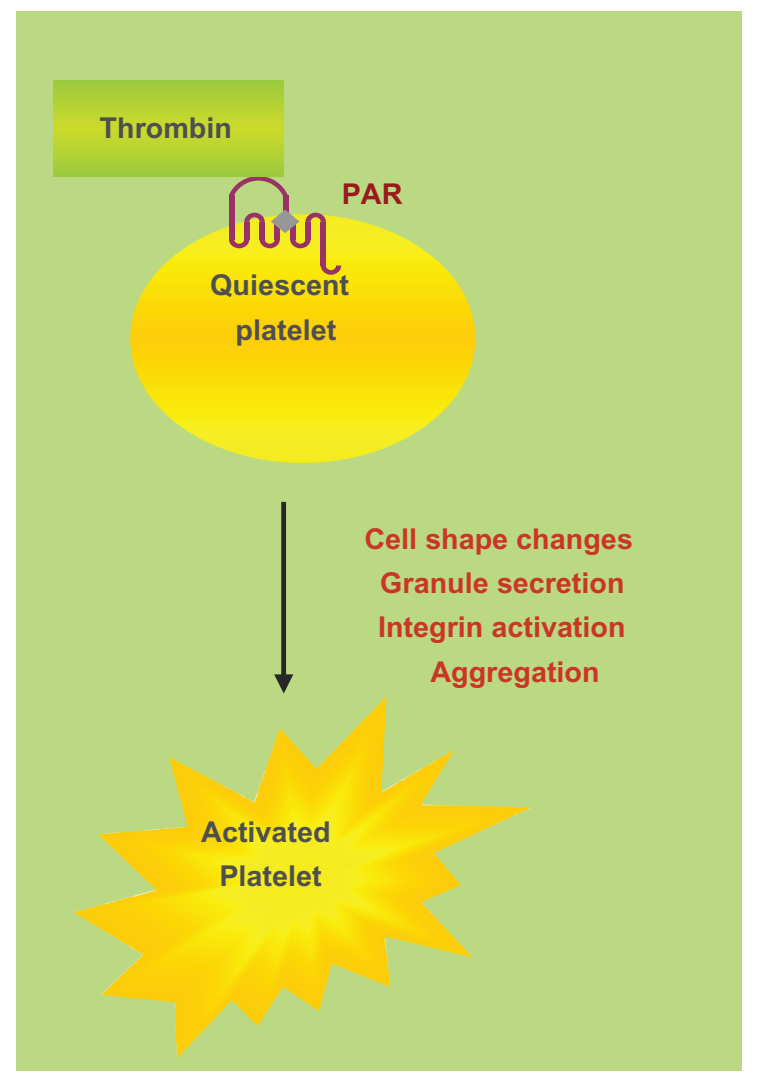

Figure IB Platelet activation by the PAR-I pathway stimulated by binding of thrombin. 
complications in patients undergoing PCI. ${ }^{29,30} \mathrm{~A}$ number of meta-analyses have demonstrated that aspirin significantly reduces the risk for vascular events in high-risk patients with a history of MI, stroke, TIA, or angina, as well as in patients without prior history of atherothrombotic disease. ${ }^{7,8,31}$ A recent meta-analysis evaluated the benefit of aspirin in primary prevention of cardiovascular disease. ${ }^{31}$ Although a significant reduction in occlusive events was observed in patients treated with aspirin (12\% proportional risk reduction, $P=0.0001)$, there was a limited clinical benefit in this setting when the absolute increase in bleeding risk was taken into account. Additionally, treatment with aspirin was not associated with a significant reduction in overall vascular mortality in this setting $(P=0.70){ }^{31}$

\section{Clopidogrel}

Clopidogrel prevents ADP-induced platelet activation and aggregation by irreversibly inhibiting the platelet ADP receptor $\mathrm{P} 2 \mathrm{Y}_{12} \cdot{ }^{32}$ The clinical efficacy of clopidogrel has been demonstrated both as an add-on to aspirin in the settings of NSTE ACS, ${ }^{10} \mathrm{PCI},{ }^{33,34}$ and STEMI, ${ }^{35,36}$ and as single antiplatelet therapy for secondary prevention. ${ }^{37}$

In the CURE (Clopidogrel in Unstable Angina to Prevent Recurrent Events) trial, a total of 12,562 patients with NSTE ACS treated with aspirin (75-325 mg daily) were randomly assigned to receive clopidogrel (loading dose of $300 \mathrm{mg}$, followed by $75 \mathrm{mg}$ daily) or placebo for 3-12 months. ${ }^{10}$ Dual antiplatelet therapy with clopidogrel and aspirin significantly reduced the primary endpoint of death from cardiovascular causes, nonfatal MI, or stroke versus aspirin alone $(9.3 \% \mathrm{vs}$ $11.4 \%$, respectively; $P<0.001)$, but it was also associated with a significantly higher major bleeding rate compared with aspirin alone $(3.7 \%$ vs $2.7 \%$, respectively; relative risk $1.38, P=0.001) .{ }^{10}$ In patients who underwent PCI (PCI-CURE), those who received clopidogrel and aspirin had a significantly lower rate of the primary endpoint of cardiovascular death, MI, or urgent target-vessel revascularization within 30 days of PCI (4.5\% vs 6.4\% with aspirin alone, $P=0.03){ }^{33}$

The CREDO (Clopidogrel for the Reduction of Events During Observation) trial evaluated the benefit of 12-month treatment with clopidogrel $(75 \mathrm{mg} /$ day) after PCI and the effect of a preprocedural clopidogrel loading dose (300 mg) in addition to aspirin therapy $(81-325 \mathrm{mg})$ in patients undergoing elective PCI ${ }^{34}$ Dual antiplatelet therapy was associated with a significant $27 \%$ relative reduction in the composite endpoint of death, MI, or stroke $(P=0.02)$ at 1 year versus aspirin alone, whereas no significant benefit of the $300 \mathrm{mg}$ loading dose of clopidogrel was apparent at 28 days. ${ }^{34}$ There was a nonsignificant increase in rate of major bleeding in the clopidogrel plus aspirin group ( $8.8 \%$ vs $6.7 \%$ with aspirin alone, $P=0.07){ }^{34}$

The COMMIT (Clopidogrel and Metoprolol in Myocardial Infarction Trial) ${ }^{35}$ and the CLARITY (Clopidogrel as Adjunctive Reperfusion Therapy-Thrombolysis in Myocardial Infarction $)^{36}$ trial demonstrated the benefit of dual antiplatelet therapy in patients with STEMI. In COMMIT, a total of 45,852 patients with STEMI treated with aspirin also received either clopidogrel $75 \mathrm{mg}$ or placebo for up to 4 weeks in hospital or until discharge. ${ }^{35}$ The rate of the composite endpoint of death, reinfarction, or stroke was significantly lower in patients receiving clopidogrel plus aspirin versus those receiving aspirin alone $(9.2 \%$ vs $10.1 \%, P=0.002) .{ }^{35}$ A significant reduction in all-cause death (coprimary endpoint) was also noted with clopidogrel plus aspirin (7.5\% vs $8.1 \%$ with aspirin alone, $P=0.03) .{ }^{35}$ In CLARITY, a total of 3491 patients with STEMI treated with aspirin and fibrinolytic therapy were randomized to receive either clopidogrel (300 mg loading dose followed by $75 \mathrm{mg} /$ day) or placebo. ${ }^{36}$ The incidence of the primary efficacy endpoint (composite of an occluded infarct-related artery on angiography or death or recurrent MI before angiography) was significantly reduced in the clopidogrel plus aspirin group versus aspirin alone (15\% vs $21.7 \%, P<0.001) .{ }^{36}$

The CAPRIE (Clopidogrel versus Aspirin in Patients at Risk of Ischemic Events) trial evaluated the efficacy of clopidogrel $75 \mathrm{mg}$ versus aspirin $325 \mathrm{mg}$ in secondary prevention of atherothrombotic disease in 19,185 patients with prior MI (onset within 35 days before randomization), stroke/TIA (onset $\geq 1$ week and $\leq 6$ months before randomization), or symptomatic PAD. ${ }^{37}$ The incidence of the primary composite endpoint of ischemic stroke, MI, and vascular death was $5.3 \%$ in the clopidogrel arm and $5.8 \%$ in the aspirin arm, a relative risk reduction of $8.7 \%$ $(P=0.043) .{ }^{37}$ More recently, the CHARISMA (Clopidogrel for High Atherothrombotic Risk and Ischemic Stabilization, Management, and Avoidance) trial included 15,603 patients with either clinically documented atherothrombotic disease or multiple risk factors but without documented atherothrombotic disease. ${ }^{38}$ Patients enrolled in CHARISMA received either clopidogrel ( $75 \mathrm{mg}$ /day) plus low-dose aspirin (75-162 mg daily) or placebo plus low-dose aspirin for a median of 28 months. There was no significant difference in the rate of the primary efficacy endpoint (MI, stroke, or cardiovascular death) between the two treatment groups (6.8\% in the clopidogrel plus aspirin group and $7.3 \%$ in the 
aspirin alone group, $P=0.22) .{ }^{38}$ Treatment with clopidogrel plus aspirin led to a nonsignificant increase in rates of severe bleeding $(1.7 \%$ vs $1.3 \%, P=0.09)$ and fatal bleeding $(0.3 \%$ vs $0.2 \% ; P=0.17) .{ }^{38}$ Prespecified subgroup analyses revealed that patients with established atherothrombotic disease $(\mathrm{N}=12,153)$ had a significant reduction in the primary endpoint following treatment with clopidogrel plus aspirin versus aspirin $(6.9 \%$ vs $7.9 \%, P=0.046)$, whereas patients with multiple risk factors alone $(\mathrm{N}=3284)$ experienced a nonsignificant increase in the rate of primary endpoint with dual antiplatelet therapy (6.6\% vs 5.5\% with aspirin alone, $P=0.20) .{ }^{38}$ Additionally, in a post hoc subgroup analysis of the CHARISMA trial, patients with documented prior MI, ischemic stroke, or symptomatic PAD $(\mathrm{N}=9478)$, also known as the "CAPRIE-like" cohort, had significantly lower rates of cardiovascular death, MI, or stroke when receiving clopidogrel plus aspirin than when treated with placebo plus aspirin $(7.3 \%$ vs $8.8 \%$, respectively; $P=0.01) .{ }^{39}$ However, moderate bleeding in the "CAPRIE-like" cohort of CHARISMA was significantly higher in the clopidogrel plus aspirin group versus the placebo plus aspirin group $(2.0 \%$ vs $1.3 \%, P=0.004) .{ }^{39}$

The CURRENT-OASIS 7 (Clopidogrel Optimal Loading Dose Usage to Reduce Recurrent Events/Optimal Antiplatelet Strategy for Interventions) trial evaluated the effect of standard (300 mg loading dose plus $75 \mathrm{mg}$ once daily [qd] maintenance dose) and higher-dosing regimens (600 mg loading dose plus $150 \mathrm{mg}$ qd maintenance dose for 7 days followed by $75 \mathrm{mg}$ qd maintenance dose) of clopidogrel and aspirin (high-dose regimen of 300-325 mg qd and standarddose regimen of 75-100 mg qd) on cardiovascular outcomes and bleeding complications in 25,087 patients with ACS with planned early ( $<24$ hours) invasive management with intended PCI. ${ }^{40}$ No significant difference in incidence of the primary composite endpoint of cardiovascular death, MI, or stroke at Day 30 was observed in the overall patient population between the two clopidogrel treatment arms (4.4\% standard-dose clopidogrel vs $4.2 \%$ high-dose clopidogrel; $P=0.370) .{ }^{41}$ However, treatment with high-dose clopidogrel resulted in a significant reduction in incidence of cardiovascular events versus standard-dose clopidogrel in patients who underwent PCI $(3.9 \%$ vs $4.5 \%, P=0.036)$, with a significant reduction in incidence of $\mathrm{MI}(2.0 \%$ vs $2.6 \%, P=0.012) .{ }^{42}$ Treatment with high-dose clopidogrel was also associated with a significant $42 \%$ relative reduction in the rate of stent thrombosis at Day 30 (definite stent thrombosis confirmed by angiography) versus standard-dose clopidogrel (hazard ratio [HR] 0.58; $P=0.001) .{ }^{41}$ In patients undergoing PCI, treatment with high-dose clopidogrel was associated with a significantly higher rate of CURRENTdefined major bleeding (1.6\% vs $1.1 \%$ with standard-dose clopidogrel; $P=0.009)$, CURRENT-defined severe bleeding ( $1.1 \%$ vs $0.8 \%$, respectively; $P=0.06)$, and red blood cell transfusion of two or more units $(1.3 \%$ vs $0.9 \%$, respectively; $P=0.019) .{ }^{42}$ Although no significant difference in the incidence of cardiovascular outcomes was observed in the overall patient population between the two aspirin treatment groups, a significant interaction between high-dose versus standard-dose aspirin and high-dose clopidogrel was observed, with significant reduction in incidence of cardiovascular death, MI, or stroke in patients administered aspirin at $300-325 \mathrm{mg}$ qd $(3.8 \%$ vs $4.6 \%, P=0.036) .{ }^{41}$

\section{New P2Y ${ }_{12}$ inhibitors \\ Prasugrel}

Prasugrel, a novel thienopyridine inhibitor of the platelet P2Y ${ }_{12}$ ADP receptor, exhibits faster and more potent platelet inhibition than clopidogrel. ${ }^{43,44}$ The clinical efficacy and safety of prasugrel was evaluated in the TRITON (Trial to Assess Improvement in Therapeutic Outcomes by Optimizing Platelet Inhibition with Prasugrel). ${ }^{9}$ TRITON compared the clinical efficacy and safety of aspirin plus prasugrel (60 mg loading dose and $10 \mathrm{mg}$ daily maintenance dose) versus aspirin plus clopidogrel (300 mg loading dose and $75 \mathrm{mg}$ daily maintenance dose) in 13,608 patients with moderate- to high-risk ACS scheduled for PCI after diagnostic angiography. ${ }^{9}$ The primary endpoint (cardiovascular death, nonfatal MI, or nonfatal stroke) was significantly less common with prasugrel plus aspirin than with clopidogrel plus aspirin (9.9\% vs $12.1 \%$, respectively; $P<0.001) .{ }^{9}$ However, the rates of bleeding were significantly higher with aspirin plus prasugrel (major bleeding: $2.4 \%$ vs $1.8 \%$ with aspirin plus clopidogrel, $P=0.03$; life-threatening bleeding: $1.4 \%$ vs $0.9 \%$, respectively; $P=0.01$; and fatal bleeding: $0.4 \%$ vs $0.1 \%$, respectively; $P=0.002) .{ }^{9}$ Additionally, transfusions were required significantly more often in patients receiving aspirin plus prasugrel (4\% vs $3 \%$ with aspirin plus clopidogrel, $P<0.001) .{ }^{9}$ In patients undergoing coronary artery bypass grafting $(\mathrm{CABG} ; \mathrm{N}=368)$, the incidence of TIMI (thrombolysis in myocardial infarction) major bleeding was more than four-fold higher in patients receiving aspirin plus prasugrel compared with patients receiving aspirin plus clopidogrel (13.4\% vs $3.2 \%, P<0.001) .{ }^{9}$ The observed increase in bleeding events prompted several post hoc analyses to determine the net clinical effect of aspirin plus prasugrel in various patient subgroups. Patients with 
stroke or TIA had a net clinical harm from aspirin plus prasugrel (HR 1.54, $P=0.04$ ), whereas patients $\geq 75$ years of age and those weighing $<60 \mathrm{~kg}$ experienced no net benefit from aspirin plus prasugrel. ${ }^{9}$ In patients with STEMI, on the other hand, therapy with aspirin plus prasugrel was associated with a significant net clinical benefit, without excess bleeding risk. ${ }^{45}$ Additionally, treatment with aspirin plus prasugrel demonstrated significant clinical benefit in patients with diabetes $^{46}$ and in patients who received at least one stent. ${ }^{47}$ Taking into account the variable net clinical effect and risks of aspirin plus prasugrel in different patient groups, careful assessment of patient characteristics is essential prior to initiation of therapy.

\section{Ticagrelor (AZD6I40)}

Ticagrelor (AstraZeneca), a novel nonthienopyridine, direct-acting (not a prodrug) oral inhibitor of the $\mathrm{P}_{2} \mathrm{Y}_{12}$ ADP receptor, is characterized by a rapid onset of action ( 2 hours to peak platelet inhibition) and a relatively rapid (12 hours) reversal of platelet inhibition. ${ }^{48}$ Ticagrelor has demonstrated greater potency and consistency of platelet inhibition compared with clopidogrel. ${ }^{49}$ The efficacy and safety of ticagrelor in combination with aspirin was evaluated in the phase 3 PLATO (Platelet Inhibition and Clinical Outcomes) trial in patients with ACS, with or without ST segment elevation. ${ }^{50}$ Patients $(\mathrm{N}=18,624)$ were randomized to ticagrelor (administered as a $180 \mathrm{mg}$ loading dose plus $90 \mathrm{mg}$ twice daily) plus aspirin or clopidogrel (300-600 mg loading dose plus $75 \mathrm{mg} \mathrm{qd)}$ plus aspirin. The primary endpoint was a composite of death from vascular causes, MI, or stroke. Treatment with ticagrelor led to a significant reduction in the incidence of the composite endpoint versus clopidogrel $(9.8 \%$ vs $11.7 \% ; P<0.001)$. Importantly, ticagrelor demonstrated a significant reduction in mortality from any cause $(4.5 \% \mathrm{vs}$ $5.9 \% ; P<0.001)$ after 1 year, with no significant differences in rate of major bleeding, defined according to trial-specific or TIMI criteria. ${ }^{50}$ The ticagrelor treatment group did show a significantly higher rate of non-CABGrelated major bleeding whether defined according to study-specific criteria $(4.5 \%$ vs $3.8 \%, P=0.03)$ or TIMI criteria $(2.8 \%$ vs $2.2 \%, P=0.03) .{ }^{50}$ Ticagrelor was also associated with significantly higher rates of other adverse events versus clopidogrel, including dyspnea (13.8\% vs $7.8 \%, P<0.001)$, increase in serum uric acid from baseline (15\% vs $7 \%, P<0.001)$, and increase in serum creatinine from baseline (11\% vs 9\%, $P<0.001)$. Phase 3 trials with another novel, intravenous $\mathrm{P} 2 \mathrm{Y}_{12}$ ADP receptor antagonist, cangrelor, have been terminated due to lack of efficacy versus clopidogrel in interim data analyses. ${ }^{51}$

\section{Elinogrel (PRT060 I28)}

Elinogrel (Portola/Novartis) is a novel nonthienopyridine, direct-acting, reversible, and competitive inhibitor of the P2Y ${ }_{12}$ ADP receptor that can be administered orally or intravenously. ${ }^{52}$ Elinogrel is not metabolized by hepatic cytochrome P (CYP)450 enzymes and is characterized by immediate and near maximal platelet inhibition following intravenous administration with a half-life of 12 hours. ${ }^{52,53}$ The efficacy and safety of elinogrel was evaluated versus clopidogrel in the phase 2 INNOVATE-PCI trial in patients undergoing nonurgent PCI. ${ }^{53}$ Patients $(\mathrm{N}=652)$ were randomized to clopidogrel administered as a 300-600 mg loading dose plus $75 \mathrm{mg}$ daily after PCI $(\mathrm{N}=208)$, elinogrel administered as a $120 \mathrm{mg}$ intravenous bolus and $100 \mathrm{mg}$ oral dose plus $100 \mathrm{mg}$ twice daily orally after PCI $(\mathrm{N}=201)$, or elinogrel administered as a $120 \mathrm{mg}$ intravenous bolus and $150 \mathrm{mg}$ oral dose plus $150 \mathrm{mg}$ twice daily orally after PCI $(\mathrm{N}=207) .{ }^{53}$

The rates of TIMI major or TIMI minor bleeding in the elinogrel and clopidogrel treatment groups were similar at both the 24-hour and 120-day timepoints. ${ }^{53}$ Compared with therapy with clopidogrel, treatment with elinogrel was associated with a dose-dependent increase in rate of bleeding requiring medical attention, mostly occurring at the vascular access site during the periprocedural period, a higher rate of dyspnea, and a higher rate of transaminase elevation. ${ }^{53}$ Treatment with elinogrel was associated with a rate of the composite ischemic endpoint that was comparable with that observed with clopidogrel at both 24 hours and 120 days; the degree of inhibition of peak platelet aggregation induced by $5 \mu \mathrm{M}$ ADP, however, was significantly greater with both elinogrel regimens at both 24 hours and 30 days. ${ }^{53}$ Furthermore, there were no differences in periprocedural rates of troponin elevation between the elinogrel and clopidogrel treatment groups. ${ }^{53}$ Initiation of a phase 3 program designed to evaluate the efficacy and safety of elinogrel in patients with chronic coronary heart disease is anticipated in 2011.

Although prasugrel, ticagrelor, and elinogrel have all demonstrated more potent platelet inhibition than clopidogrel, these agents target only the $\mathrm{P} 2 \mathrm{Y}_{12}$ ADP receptor and do not significantly inhibit other platelet activation pathways. Therefore, even in the presence of these agents, other platelet activation pathways, including the PAR-1 pathway activated by thrombin, remain functional, allowing continued platelet aggregation and thrombosis. 


\section{Limitations of current antiplatelet therapy}

Residual risk for thrombotic/ischemic events

Despite receiving dual antiplatelet therapy with aspirin and a P2 $\mathrm{Y}_{12}$ inhibitor, a considerable number of patients continue to experience recurrent thrombotic events (Figure 2). ${ }^{8-10,50}$ For example, the CURE trial demonstrated a $20 \%$ risk reduction in cardiovascular death, nonfatal MI, and nonfatal stroke in patients receiving clopidogrel plus aspirin versus aspirin alone, but the risk for an ischemic event at 12 months in patients receiving clopidogrel plus aspirin was still substantial $(9.3 \%) .{ }^{10}$ Similarly, in TRITON and PLATO, the most recent large trials of antiplatelet therapy in patients with ACS, approximately $10 \%$ of patients receiving dual antiplatelet therapy experienced cardiovascular death, MI, or stroke. ${ }^{9,50}$ As discussed previously, dual antiplatelet therapy with aspirin and clopidogrel did not provide a significant clinical benefit versus aspirin alone in the overall population of the CHARISMA trial, and even among the cohort of patients with prior MI, stroke, or PAD, in whom a significant clinical benefit versus aspirin alone was observed, over $7 \%$ of patients receiving clopidogrel plus aspirin experienced an ischemic event. ${ }^{39}$ Thus, a considerable number of patients remain at residual risk for thrombotic events after both acute and longer-term treatment with dual antiplatelet therapy.

Residual risk of ischemic events with aspirin and a P2 $\mathrm{Y}_{12}$ inhibitor has been attributed to the fact that although multiple pathways contribute to platelet activation, these agents do not inhibit pathways other than those stimulated by TxA and ADP, respectively. ${ }^{6} \mathrm{TxA}_{2}$ and $\mathrm{ADP}$ are involved in initial platelet recruitment and adhesion during both hemostasis and thrombosis. Other platelet activation pathways, including the PAR-1 pathway activated by thrombin (the most potent platelet activator), remain active in the presence of current antiplatelet agents. The lack of an inhibitory effect of current therapies on multiple platelet activation pathways allows for continued platelet reactivity in the presence of potent agonists, such as thrombin (Figure 1B), thereby increasing the risk for recurrent thrombotic events, including death. New therapies that target pathways that are not affected by aspirin or $\mathrm{P}_{2} \mathrm{Y}_{12}$ inhibitors could provide complementary and more comprehensive inhibition of platelet activation, and thereby contribute to greater inhibition of platelet-mediated thrombosis, when used in combination with the current standardof-care therapies. Importantly, preclinical evidence suggests that the principal thrombin receptor on platelets is critical for uncontrolled thrombus growth and propagation into the arterial lumen, but it is not required for initial platelet deposition that may help facilitate vascular repair and does not interfere with thrombin-mediated conversion of fibrinogen into fibrin. Mice with genetic inactivation of the primary thrombin receptor exhibit markedly reduced platelet accumulation and thrombus growth but have normal initial platelet deposition and fibrin accumulation, and they do not bleed spontaneously. ${ }^{54}$ Thus, inhibition of PAR-1 could potentially reduce the risk of thrombosis without excess bleeding risk.

\section{CV death, MI, or Stroke}

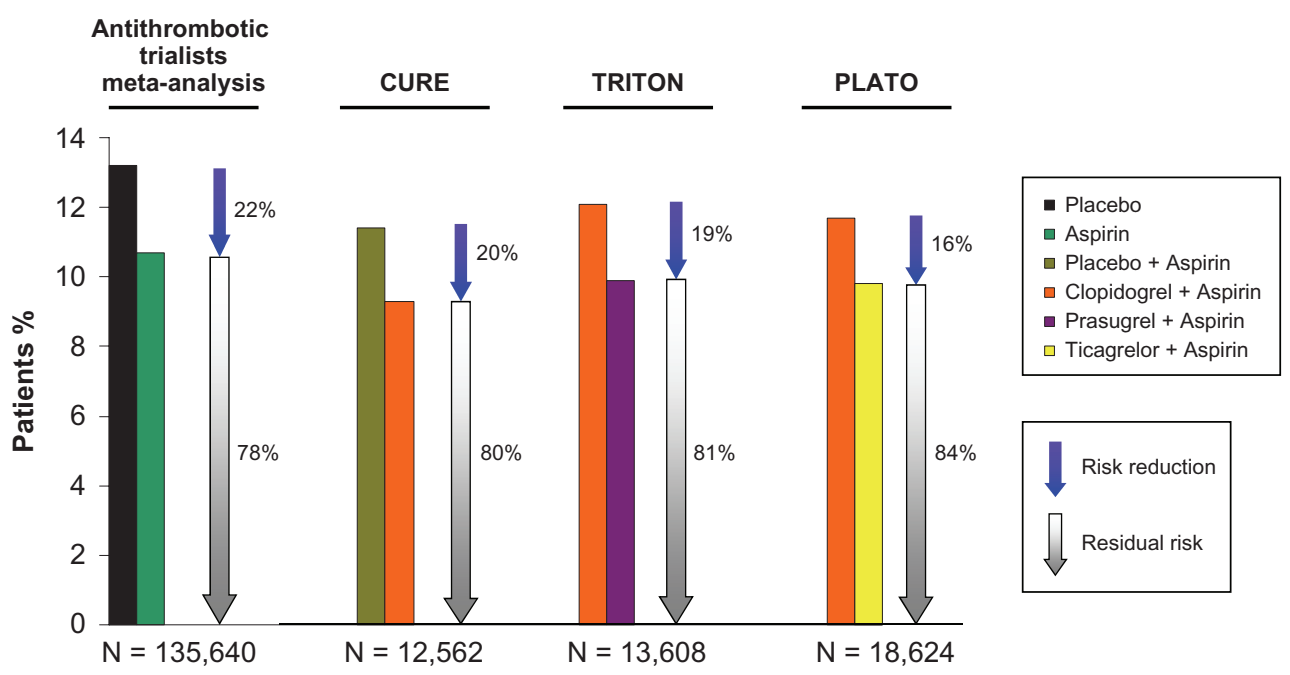

Figure 2 Risk reduction and residual risk for cardiovascular (CV) death, myocardial infarction (MI), or stroke in patients receiving antiplatelet therapy. ${ }^{8-10,50}$ Abbreviations: CURE, Clopidogrel in Unstable Angina to Prevent Recurrent Events; PLATO, Platelet Inhibition and Clinical Outcomes; TRITON, Trial to Assess Improvement in Therapeutic Outcomes by Optimizing Platelet Inhibition with Prasugrel. 


\section{Bleeding risk}

Increased bleeding risk is another significant clinical limitation of current oral antiplatelet therapies. Aspirin has been associated with a dose-dependent increase in bleeding risk, particularly gastrointestinal bleeding, ${ }^{55,56}$ even at low doses. ${ }^{55}$ The addition of clopidogrel to aspirin has been shown to further increase the risk of bleeding, as well as the need for transfusions. ${ }^{10,33,34,57}$ In an analysis from the CURE trial, the incidence of major bleeding increased significantly with higher aspirin doses ( $\leq 100 \mathrm{mg}, 101-199 \mathrm{mg}$, and $\geq 200 \mathrm{mg}$ ) in both the clopidogrel plus aspirin and the aspirin monotherapy arms, indicating a dose-dependent effect of aspirin on bleeding risk. ${ }^{57}$ In CHARISMA, the rate of severe bleeding was 1.7\% in the clopidogrel plus aspirin group versus $1.3 \%$ in the aspirin group $(P=0.09)$, and the rate of moderate bleeding was $2.1 \%$ with clopidogrel plus aspirin versus $1.3 \%$ with aspirin $(P<0.001) .{ }^{38}$ In TRITON, the combination of aspirin and prasugrel was associated with a significantly greater risk of TIMI major, life-threatening, fatal, and CABG-related bleeding, as well as a significantly higher rate of transfusions than aspirin plus clopidogrel. ${ }^{9}$ Increased bleeding risk with prasugrel is most likely related to its greater inhibitory effect on ADPinduced platelet aggregation compared with clopidogrel.

Increased bleeding risk with aspirin and the combination of aspirin plus an ADP receptor inhibitor has been attributed to the fact that aspirin and $\mathrm{P} 2 \mathrm{Y}_{12}$ inhibitors interfere with the $\mathrm{TxA}_{2}$ and ADP platelet activation pathways, which are essential for normal hemostasis. ${ }^{3-6,22}$ These considerations underscore the need for novel agents that provide more comprehensive platelet inhibition without interfering with platelet activation pathways critical for hemostasis, for greater protection against thrombotic events and no incremental bleeding risk.

Whereas bleeding and blood transfusions are clearly undesirable outcomes on their own, these events have also recently been shown to represent independent predictors of short- and long-term mortality in patients with atherothrombotic disease. ${ }^{58,59}$ An analysis from four multicenter, randomized clinical trials in 26,452 patients with NSTE ACS showed a significant increase in unadjusted rates of 30-day and 6-month mortality with greater bleeding severity (the HRs for 6-month mortality ranged from 1.4 for mild bleeding to 2.1 for moderate bleeding and 7.5 for severe bleeding; $P<0.001) .{ }^{59}$ In a separate study of 24,112 patients with ACS, those who underwent blood transfusion had significantly higher rates of 30 -day mortality ( $8 \%$ vs $3.1 \%, P<0.001$ ), MI $(25.2 \%$ vs $8.2 \%, P<0.001)$, and the composite of death or MI $(29.2 \%$ vs $10.0 \%, P<0.001)$ than patients who did not require a transfusion. ${ }^{58}$ Some of the increase in adverse outcomes may also be related to the suspension of needed antithrombotic therapies.

\section{Variability in response to antiplatelet therapy}

Several studies have documented variable responsiveness of platelets to therapy with aspirin and/or clopidogrel. ${ }^{32,60-62}$ Although a standardized definition and methodology for measurement of low responsiveness to antiplatelet therapy has not been established, sufficient evidence supports the concept that persistence of enhanced platelet reactivity despite the use of aspirin ${ }^{61,63}$ or clopidogrel ${ }^{60,64-66}$ is clinically relevant. For example, Chen et a ${ }^{63}$ evaluated responsiveness to aspirin in 468 patients with stable coronary artery disease (CAD) using the point-of-care VerifyNow Aspirin assay, and found that patients with aspirin resistance (defined as aspirin reaction unit $\geq 550$, and observed in $27.4 \%$ of patients) were at almost three-fold higher risk of cardiovascular death, MI, unstable angina requiring hospitalization, stroke, or a TIA than aspirin-sensitive patients ( $15.6 \%$ vs $5.3 \%$, respectively; $P<0.001)$. Similarly, a correlation between a low level of inhibition of ADP-induced platelet aggregation in response to clopidogrel and recurrence of ischemic events has been documented in several studies in patients with ACS and those undergoing PCI (Figure 3). ${ }^{64-66}$

Although the mechanisms responsible for the variability and low responsiveness to aspirin and clopidogrel have not been fully

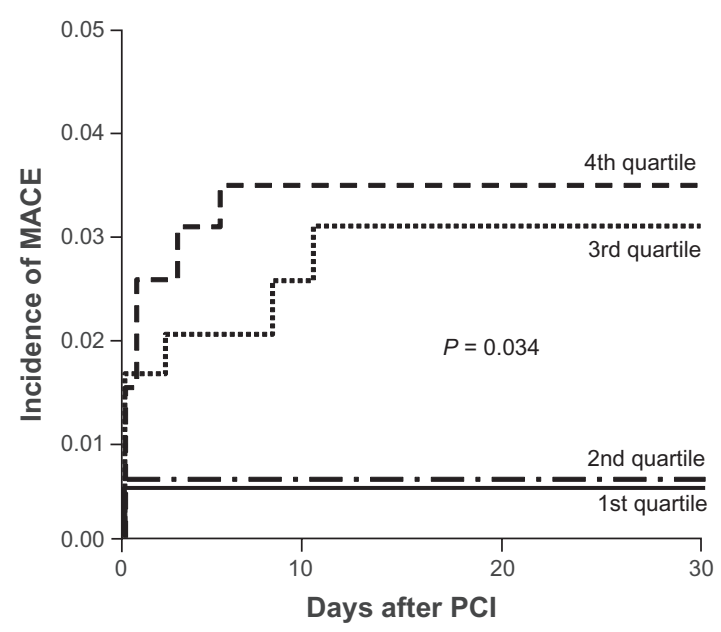

Figure 3 Cumulative incidence of MACE within 30 days after $\mathrm{PCl}$ by quartiles of ADP-induced platelet aggregation (first quartile: $<4 \%$; second: $4 \%-14 \%$; third: $15 \%-$ $32 \%$; fourth: $>32 \%$ ) in 802 patients undergoing elective $\mathrm{PCl}$ and receiving clopidogrel $600 \mathrm{mg}$ loading dose.

Reprinted from the Journal of the American College of Cardiology, 48, Hochholzer W, Trenk D, Bestehorn HP, Fischer B, Valina CM, Ferenc M, Gick M, Caputo A, Büttner HJ, Neumann FJ. Impact of the Degree of Peri-Interventional Platelet Inhibition After Loading With Clopidogrel on Early Clinical Outcome of Elective Coronary Stent Placement, 1742-1750, Copyright 2006, with permission from Elsevier. ${ }^{65}$

Abbreviations: ADP, adenosine diphosphate; MACE, major adverse cardiac events; $\mathrm{PCl}$, percutaneous coronary intervention. 
elucidated, recent analyses suggest that genetic polymorphisms of the CYP450 enzymes can significantly modulate individual response to clopidogrel and are important determinants of prognosis. ${ }^{67-69}$ Clopidogrel is a prodrug that is converted to an active metabolite by CYP enzymes. ${ }^{48} \mathrm{~A}$ recent study of patients with acute $\mathrm{MI}$ treated with clopidogrel demonstrated that the carriers of the CYP2C19*2 allelic variant (CYP2C19) had a significantly higher rate of ischemic events (death, nonfatal MI, or urgent revascularization) than the noncarriers (10.9 events per 100 patient-years vs 2.9 events per 100 patient-years, respectively; adjusted HR 5.38, $P<0.0001) .{ }^{67}$ Similarly, in a French registry of patients with acute $\mathrm{MI}$ treated with clopidogrel, those patients who had any two loss-of-function CYP2C19 variants had a significantly higher rate of death, nonfatal MI, or stroke ( $21.5 \%$ vs $13.3 \%$ in patients with none of the loss-of-function alleles, adjusted HR 1.98); the increased risk was particularly prominent among patients undergoing PCI ${ }^{69}$ Additionally, in TRITON, patients treated with clopidogrel who were carriers of one or more reduced-function CYP2C19 alleles had a significantly higher rate of cardiovascular events than noncarriers (12.1\% vs $8.0 \%$, respectively; $P=0.01){ }^{.68}$ this finding was not observed in patients treated with prasugrel. Clopidogrel has also demonstrated potential for interaction with other drugs metabolized by $\mathrm{P} 450$ enzymes, such as proton pump inhibitors, and this interaction can significantly reduce the peak plasma concentrations of the active metabolite of clopidogrel and diminish its platelet-inhibitory effects. ${ }^{70,71}$ A trial of clopidogrel with or without omeprazole in CAD demonstrated no evidence of an adverse cardiovascular interaction between omeprazole and clopidogrel..$^{72}$

In summary, despite the proven clinical benefits of current oral antiplatelet agents, they are associated with significant residual risk for ischemic events, increased bleeding risk, and variable patient responsiveness, underscoring the need for novel antiplatelet agents that can provide further reductions in ischemic events without increased bleeding liability.

\section{PAR-I/thrombin receptor antagonists (TRAs): a novel class of oral antiplatelet agents}

The platelet PAR-1 receptor is an important mediator of platelet activation that contributes to thrombosis but may not be essential for hemostasis. Importantly, current oral antiplatelet agents do not inhibit the thrombin-PAR-1 platelet activation pathway, and novel oral antiplatelet agents targeting the PAR-1 pathway may provide more comprehensive platelet inhibition and incremental clinical benefits, potentially without increased bleeding risk. Therefore, inhibition of
PAR-1 represents a rational approach to development of novel antiplatelet agents, and two oral PAR-1 inhibitors are currently in advanced clinical development: Atopaxar (E5555) (Eisai) is currently being evaluated in phase 2 trials, whereas vorapaxar (SCH530348) (Merck) is undergoing evaluation in two large phase 3 trials.

\section{Atopaxar (E5555)}

Atopaxar is a PAR-1 antagonist that has demonstrated potent inhibition of thrombin receptor agonist peptide (TRAP)induced platelet aggregation in preclinical studies, ${ }^{73}$ as well as the inhibition of thrombin-stimulated release of soluble CD40 ligand (sCD40L) and interleukin 6 (IL-6), and the expression of P-selectin on human endothelial cells. ${ }^{74}$

The safety and efficacy of atopaxar has been evaluated in two phase 2 trials (J-LANCELOT) in Japanese patients with ACS $(\mathrm{N}=241)$ or high-risk CAD $(\mathrm{N}=263) .{ }^{75}$ Patients were allocated to atopaxar plus standard therapy or placebo plus standard therapy. ${ }^{75}$ Treatment with atopaxar was associated with similar rates of TIMI-defined major, minor, and minimal bleeds requiring medical attention versus treatment with placebo in patients with ACS $(5.0 \%$ with atopaxar [all doses] vs $6.6 \%$ with placebo), as well as in patients with CAD ( $1.5 \%$ in both the atopaxar [all doses] and placebo groups). ${ }^{75}$ Treatment with atopaxar led to numerically lower rates of major adverse cardiac events versus placebo in patients with ACS (5.0\% vs 6.6\%, respectively; $P=0.73)$ and in patients with CAD $(1.0 \%$ vs $4.5 \%$, respectively; $P=0.066) .{ }^{75}$ There were no significant differences in rates of adverse events or serious adverse events between the atopaxar and placebo treatment groups in either patient population. ${ }^{75}$ Treatment with atopaxar led to higher prevalence of hepatic enzyme elevation versus treatment with placebo in patients with ACS (23.3\% vs $11.5 \%$, respectively; $P=0.064)$, as well as in patients with CAD $(10.2 \%$ vs $1.5 \% ; P=0.032) .{ }^{75} \mathrm{~A}$ trend toward dose-dependent QTcF prolongation with atopaxar was observed in patients with $\operatorname{ACS}(P=0.074)$, and a significant, dose-dependent prolongation of QTcF interval with atopaxar was reported in patients with $\mathrm{CAD}(P=0.026){ }^{75}$

The LANCELOT ACS trial evaluated safety and efficacy of atopaxar in combination with aspirin and clopidogrel or ticlopidine versus placebo plus aspirin and clopidogrel or ticlopidine in patients with NSTE ACS $(\mathrm{N}=603) .{ }^{76}$ Treatment with atopaxar was associated with similar rates of any CURE-defined bleeding (3.1\% with atopaxar vs $2.2 \%$ with placebo; $P=0.63)$ and any TIMI-defined bleeding $(9.3 \%$ with atopaxar vs $10.1 \%$ with placebo; $P=0.77) .{ }^{76}$ Similar rates of cardiovascular death, MI, stroke, or recurrent ischemia 
were observed between the atopaxar $(\mathrm{N}=461)$ and placebo $(\mathrm{N}=142)$ groups $(8.0 \%$ vs $7.8 \%$ with placebo; $P=0.93){ }^{76}$ However, a trend toward lower incidence of cardiovascular death, MI, or stroke was observed in patients treated with atopaxar versus placebo $(3.3 \%$ vs $5.6 \% ; P=0.20) .{ }^{76} \mathrm{~A}$ significant, $33 \%$ relative reduction in the incidence of Holter-detected ischemia was observed at 48 hours postdosing in patients receiving atopaxar $(18.7 \%$ vs $28.1 \%$ with placebo; $P=0.02) .{ }^{76}$ Treatment with atopaxar led to a dose-dependent elevation in liver function enzymes, and the highest maintenance doses (100 mg and $200 \mathrm{mg}$ ) of atopaxar were associated with significant prolongation of QTc interval versus placebo $(P<0.05$ for each comparison). ${ }^{76}$ The elevations in liver enzymes and QTc interval prolongations seen in LANCELOT were also apparent in the J-LANCELOT study discussed previously but were not reported in the phase 2 trials with a PAR-1 antagonist vorapaxar (discussed in the following section).

\section{Vorapaxar (SCH530348)}

Vorapaxar, an orally bioavailable PAR-1 antagonist, is a potent and selective inhibitor of thrombin-induced platelet aggregation that does not interfere with clotting parameters (such as prothrombin time). ${ }^{77}$ The phase 2 TRA-PCI (Thrombin Receptor Antagonist-Percutaneous Coronary Intervention) trial evaluated the safety and efficacy of vorapaxar (administered as either a $10 \mathrm{mg}, 20 \mathrm{mg}$, or $40 \mathrm{mg}$ loading dose on Day 1, followed by a maintenance dose of $0.5 \mathrm{mg} \mathrm{qd}, 1 \mathrm{mg} \mathrm{qd}$, or $2.5 \mathrm{mg}$ qd for 59 days) used in combination with standard oral antiplatelet therapy (aspirin and clopidogrel) and an antithrombin agent (heparin or bivalirudin) in patients in whom nonurgent PCI was planned. ${ }^{78}$ In patients who actually underwent PCI (primary cohort), there was no significant difference in the incidence of TIMI major bleeding and minor bleeding among patients receiving the standard-of-care therapy plus vorapaxar (all doses) versus standard-of-care therapy alone $(2.8 \%$ and $3.3 \%$, respectively; $P=\mathrm{NS}) .{ }^{78}$ Although the trial was not powered to detect a difference in clinical endpoints, the incidence of death or major adverse cardiac events at 60 days was reduced from $8.6 \%$ in the standard-of-care alone therapy group to $5.7 \%$ in the group receiving vorapaxar plus standard of care due to a reduced rate of MI, although this difference did not achieve statistical significance. ${ }^{78}$ A pharmacodynamic substudy of TRA-PCI demonstrated that the complete ( $\geq 80 \%)$ inhibition of TRAP-induced platelet aggregation is achieved most rapidly and most consistently with the $40 \mathrm{mg}$ loading dose of vorapaxar, and that the maintenance doses of $1.0 \mathrm{mg}$ qd and $2.5 \mathrm{mg}$ qd sustained complete inhibition at 30 days and 60 days. ${ }^{78}$ A separate pharmacodynamic study demonstrated that in the absence of the loading dose, the $2.5 \mathrm{mg}$ qd maintenance dose provides the complete ( $\geq 80 \%)$ inhibition of TRAP-induced platelet aggregation more consistently than the $1.0 \mathrm{mg}$ qd maintenance dose. ${ }^{79}$ Of note, vorapaxar did not interfere with platelet aggregation induced by other agonists (eg, ADP, arachidonic acid, or collagen), ${ }^{80}$ demonstrating that it is a specific PAR-1 inhibitor that does not inhibit platelet activation pathways required for hemostasis. The safety and efficacy of oral vorapaxar were also documented in a phase 2 trial in Japanese patients with NSTE ACS in whom PCI was planned. ${ }^{81}$ In this study, the incidence of TIMI major or minor bleeding in patients receiving vorapaxar plus the standard-ofcare therapy (aspirin, ticlopidine, and heparin) was similar to the rate observed with the standard-of-care therapy alone, whereas the incidence of nonfatal MI was significantly lower in the vorapaxar group (all doses: $16.9 \%$ vs $42.9 \%$ in the control group, $P=0.013) .{ }^{81}$ Furthermore, in a phase 2 trial in Japanese subjects with prior ischemic stroke, the addition of vorapaxar to aspirin was not associated with any episodes of TIMI major, TIMI minor, or non-TIMI bleeding. ${ }^{82}$ These results collectively suggest that the addition of vorapaxar to standard therapy may provide incremental reductions in ischemic events. This hypothesis is currently being evaluated in two large phase 3 trials, one in patients presenting with NSTE ACS, ${ }^{83}$ and the other in secondary prevention in patients with a history of prior MI, ischemic stroke, or symptomatic PAD. ${ }^{84}$ The trial in patients presenting with NSTE ACS has completed enrollment. The prespecified number of primary and secondary efficacy events has been reached, and the results were expected to be presented in the second half of 2011. It should be noted, though, that although the trial had reached the prespecified number of primary and secondary events, it was stopped prematurely by the Data Safety Monitoring Board in January 2011 for undisclosed reasons. As a result, not all patients in this trial will have a prespecified minimum of 1-year follow-up. In the secondary prevention trial, study drug therapy has been discontinued among patients with prior ischemic stroke and those who had a stroke during the study as of January $2011,{ }^{85}$ at the recommendation of the Data Safety Monitoring Board, due to increased incidence of intracranial hemorrhage in the vorapaxar arm that was not outweighed by considerations of potential ischemic benefit. Study drug therapy in the secondary prevention trial is being continued in patients with prior MI and those with symptomatic PAD.

\section{Conclusion}

Current oral antiplatelet agents, namely aspirin and $\mathrm{P} 2 \mathrm{Y}_{12}$ ADP receptor inhibitors, have demonstrated clinical benefits 
in a wide range of patients with atherothrombotic disease. However, these agents are associated with important clinical limitations, such as the high residual risk for ischemic events, increased risk of bleeding, and variable responsiveness or resistance. Significant residual risk for ischemic events exists because aspirin and $\mathrm{P} 2 \mathrm{Y}_{12}$ ADP receptor inhibitors inhibit platelet activation pathways stimulated by $\mathrm{TxA}_{2}$ and ADP but do not affect additional platelet activation pathways contributing to thrombosis. This lack of comprehensive inhibition of platelet-mediated thrombosis, including the absence of inhibition of PAR-1-mediated platelet activation induced by thrombin, effectively exposes patients to a residual risk for thrombotic events. The increased risk of bleeding with aspirin and $\mathrm{P} 2 \mathrm{Y}_{12}$ ADP receptor inhibitors can be explained by their interference with $\mathrm{TxA}_{2}$ and ADP platelet activation pathways, which are critical for normal hemostasis. Reduced responsiveness or resistance to aspirin and clopidogrel, the causes of which remain to be fully elucidated, has been shown to be associated with increased risk for poor clinical outcomes. Taken together, these limitations of current antiplatelet agents underscore the need for agents with a novel mechanism of action that may provide more comprehensive platelet inhibition for further reductions in morbidity and mortality in patients with atherothrombotic disease. Oral PAR-1 antagonists are a promising new class of antiplatelet agents, and the first agent in this class, vorapaxar, is currently being evaluated in two large phase 3 trials.

\section{Acknowledgments}

The author thanks Roy Garcia, PhD, and Sabrina McGuigan, CMPP, for editorial and submission assistance. This assistance was funded by Schering-Plough Corporation, now Merck and Co, Inc, Whitehouse Station, NJ.

\section{Disclosure}

The author did not receive any financial compensation for this work and is fully responsible for the content of the manuscript. The funder was not involved in the development of the content for this manuscript.

\section{References}

1. Allender S, Scarborough P, Peto V, Rayner M. European cardiovascular disease statistics. 2008 edition. Department of Public Health, University of Oxford. Available from: http://www.bhf.org.uk/publications/viewpublication.aspx?ps=1001443. Accessed November 7, 2011.

2. Lloyd-Jones D, Adams R, Carnethon M, et al. Heart disease and stroke statistics - 2009 update: a report from the American Heart Association Statistics Committee and Stroke Statistics Subcommittee. Circulation. 2009;119(3):e21-e181.

3. Davì G, Patrono C. Platelet activation and atherothrombosis. $N$ Engl $J$ Med. 2007;357(24):2482-2494.
4. Meadows TA, Bhatt DL. Clinical aspects of platelet inhibitors and thrombus formation. Circ Res. 2007;100(9):1261-1275.

5. Offermanns S. Activation of platelet function through $\mathrm{G}$ protein-coupled receptors. Circ Res. 2006;99(12):1293-1304.

6. Brass LF. Thrombin and platelet activation. Chest. 2003; 124(Suppl 3):18S-25S.

7. Collaborative overview of randomised trials of antiplatelet therapy $-\mathrm{I}$ : Prevention of death, myocardial infarction, and stroke by prolonged antiplatelet therapy in various categories of patients. BMJ. 1994;308(6921): 81-106.

8. Collaborative meta-analysis of randomised trials of antiplatelet therapy for prevention of death, myocardial infarction, and stroke in high risk patients. BMJ. 2002;324(7329):71-86.

9. Wiviott $\mathrm{SD}$, Braunwald E, McCabe $\mathrm{CH}$, et al. Prasugrel versus clopidogrel in patients with acute coronary syndromes. $N$ Engl $J$ Med. 2007;357(20):2001-2015.

10. Yusuf S, Zhao F, Mehta SR, et al. Effects of clopidogrel in addition to aspirin in patients with acute coronary syndromes without ST-segment elevation. $N$ Engl J Med. 2001;345(7):494-502.

11. Anderson JL, Adams CD, Antman EM, et al. 2011 ACCF/AHA focused update incorporated into the ACC/AHA 2007 guidelines for the management of patients with unstable angina/non-ST-elevation myocardial infarction: a report of the American College of Cardiology Foundation/American Heart Association Task Force on Practice Guidelines. Circulation. March 28, 2011.

12. Antman EM, Hand M, Armstrong PW, et al. 2007 focused update of the ACC/AHA 2004 guidelines for the management of patients with ST-elevation myocardial infarction: a report of the American College of Cardiology/American Heart Association Task Force on Practice Guidelines. J Am Coll Cardiol. 2008;51(2):210-247.

13. Smith SC Jr, Allen J, Blair SN, et al. AHA/ACC guidelines for secondary prevention for patients with coronary and other atherosclerotic vascular disease: 2006 update: endorsed by the National Heart, Lung, and Blood Institute. Circulation. 2006;113(19):2363-2372.

14. Wright RS, Anderson JL, Adams CD, et al. 2011 ACCF/AHA focused update of the guidelines for the management of patients with unstable angina/non-ST-elevation myocardial infarction (updating the 2007 guideline): a report of the American College of Cardiology Foundation/American Heart Association Task Force on Practice Guidelines. Circulation. 2011;123(18):2022-2060.

15. Wasserman EJ, Shipley NM. Atherothrombosis in acute coronary syndromes: mechanisms, markers, and mediators of vulnerability. Mt Sinai J Med. 2006;73(1):431-439.

16. Behrendt D, Ganz P. Endothelial function. From vascular biology to clinical applications. Am J Cardiol. 2002;90(10C):40L-48L.

17. Viles-Gonzalez JF, Fuster V, Badimon JJ. Atherothrombosis: a widespread disease with unpredictable and life-threatening consequences. Eur Heart J. 2004;25(14):1197-1207.

18. Weiss N, Keller C, Hoffmann U, Loscalzo J. Endothelial dysfunction and atherothrombosis in mild hyperhomocysteinemia. Vasc Med. 2002;7(3):227-239.

19. Nakashima Y, Plump AS, Raines EW, et al. ApoE-deficient mice develop lesions of all phases of atherosclerosis throughout the arterial tree. Arterioscler Thromb. 1994;14(1):133-140.

20. Corti R, Fuster V, Badimon JJ, et al. New understanding of atherosclerosis (clinically and experimentally) with evolving MRI technology in vivo. Ann N Y Acad Sci. 2001;947:181-195; discussion 195-198.

21. van der Wal AC, Becker AE, van der Loos CM, Das PK. Site of intimal rupture or erosion of thrombosed coronary atherosclerotic plaques is characterized by an inflammatory process irrespective of the dominant plaque morphology. Circulation. 1994;89(1):36-44.

22. Varga-Szabo D, Pleines I, Nieswandt B. Cell adhesion mechanisms in platelets. Arterioscler Thromb Vasc Biol. 2008;28(3):403-412.

23. Coughlin SR. Protease-activated receptors in hemostasis, thrombosis and vascular biology. J Thromb Haemost. 2005;3(8):1800-1814.

24. Ossovskaya VS, Bunnett NW. Protease-activated receptors: contribution to physiology and disease. Physiol Rev. 2004;84(2):579-621. 
25. Brummel KE, Paradis SG, Butenas S, Mann KG. Thrombin functions during tissue factor-induced blood coagulation. Blood. 2002;100(1):148-152.

26. Mann KG. Thrombin formation. Chest. 2003;124(3 suppl):4S-10S.

27. Patrono C, Baigent C, Hirsh J, Roth G. Antiplatelet Drugs: American College of Chest Physicians Evidence-Based Clinical Practice Guidelines. 8th ed. Chest. 2008;133(Suppl 6):199S-233S.

28. Lewis HD Jr, Davis JW, Archibald DG, et al. Protective effects of aspirin against acute myocardial infarction and death in men with unstable angina. Results of a Veterans Administration Cooperative Study. N Engl J Med. 1983;309(7):396-403.

29. Popma JJ, Ohman EM, Weitz J, et al. Antithrombotic therapy in patients undergoing percutaneous coronary intervention. Chest. 2001; 119(Suppl 1):321S-336S.

30. Schwartz L, Bourassa MG, Lespérance J, et al. Aspirin and dipyridamole in the prevention of restenosis after percutaneous transluminal coronary angioplasty. N Engl J Med. 1988;318(26):1714-1719.

31. Baigent C, Blackwell L, Collins R, et al. Aspirin in the primary and secondary prevention of vascular disease: collaborative metaanalysis of individual participant data from randomised trials. Lancet. 2009;373(9678):1849-1860.

32. Angiolillo DJ, Guzman LA, Bass TA. Current antiplatelet therapies: benefits and limitations. Am Heart J. 2008;156(Suppl 2):S3-S9.

33. Mehta SR, Yusuf S, Peters RJ, et al. Effects of pretreatment with clopidogrel and aspirin followed by long-term therapy in patients undergoing percutaneous coronary intervention: the PCI-CURE study. Lancet. 2001;358(9281):527-533.

34. Steinhubl SR, Berger PB, Mann JT III, et al. Early and sustained dual oral antiplatelet therapy following percutaneous coronary intervention: a randomized controlled trial. JAMA. 2002;288(19):2411-2420.

35. Chen ZM, Jiang LX, Chen YP, et al. Addition of clopidogrel to aspirin in 45,852 patients with acute myocardial infarction: randomised placebo-controlled trial. Lancet. 2005;366(9497):1607-1621.

36. Sabatine MS, Cannon CP, Gibson CM, et al. Addition of clopidogrel to aspirin and fibrinolytic therapy for myocardial infarction with STsegment elevation. $N$ Engl J Med. 2005;352(12):1179-1189.

37. CAPRIE Steering Commitee. A randomised, blinded, trial of clopidogrel versus aspirin in patients at risk of ischaemic events (CAPRIE). CAPRIE Steering Committee. Lancet. 1996;348(9038):1329-1339.

38. Bhatt DL, Fox KA, Hacke W, et al. Clopidogrel and aspirin versus aspirin alone for the prevention of atherothrombotic events. $N$ Engl J Med. 2006;354(16):1706-1717.

39. Bhatt DL, Flather MD, Hacke W, et al. Patients with prior myocardial infarction, stroke, or symptomatic peripheral arterial disease in the CHARISMA trial. J Am Coll Cardiol. 2007;49(19):1982-1988.

40. Mehta SR, Bassand JP, Chrolavicius S, et al. Design and rationale of CURRENT-OASIS 7: a randomized, $2 \times 2$ factorial trial evaluating optimal dosing strategies for clopidogrel and aspirin in patients with ST and non-ST-elevation acute coronary syndromes managed with an early invasive strategy. Am Heart J. 2008;156(6):1080-1088.e1.

41. Mehta SR, Bassand JP, Chrolavicius S, et al. Dose comparisons of clopidogrel and aspirin in acute coronary syndromes. $N$ Engl J Med. 2010;363(10):930-942.

42. Mehta SR, Tanguay JF, Eikelboom JW, et al. Double-dose versus standard-dose clopidogrel and high-dose versus low-dose aspirin in individuals undergoing percutaneous coronary intervention for acute coronary syndromes (CURRENT-OASIS 7): a randomised factorial trial. Lancet. 2010;376(9748):1203-1205.

43. Jernberg T, Payne CD, Winters KJ, et al. Prasugrel achieves greater inhibition of platelet aggregation and a lower rate of non-responders compared with clopidogrel in aspirin-treated patients with stable coronary artery disease. Eur Heart J. 2006;27(10):1166-1173.

44. Wallentin L, Varenhorst C, James S, et al. Prasugrel achieves greater and faster P2Y12 receptor-mediated platelet inhibition than clopidogrel due to more efficient generation of its active metabolite in aspirin-treated patients with coronary artery disease. Eur Heart J. 2008;29(1):21-30.
45. Montalescot G, Wiviott SD, Braunwald E, et al. Prasugrel compared with clopidogrel in patients undergoing percutaneous coronary intervention for ST-elevation myocardial infarction (TRITON-TIMI 38): double-blind, randomised controlled trial. Lancet. 2009;373(9665): $723-731$.

46. Wiviott SD, Braunwald E, Angiolillo DJ, et al. Greater clinical benefit of more intensive oral antiplatelet therapy with prasugrel in patients with diabetes mellitus in the trial to assess improvement in therapeutic outcomes by optimizing platelet inhibition with prasugrelThrombolysis in Myocardial Infarction 38. Circulation. 2008;118(16): $1626-1636$.

47. Wiviott SD, Braunwald E, McCabe CH, et al. Intensive oral antiplatelet therapy for reduction of ischaemic events including stent thrombosis in patients with acute coronary syndromes treated with percutaneous coronary intervention and stenting in the TRITON-TIMI 38 trial: a subanalysis of a randomised trial. Lancet. 2008;371(9621): 1353-1363.

48. Raju NC, Eikelboom JW, Hirsh J. Platelet ADP-receptor antagonists for cardiovascular disease: past, present and future. Nat Clin Pract Cardiovasc Med. 2008;5(12):766-780.

49. Husted S, Emanuelsson H, Heptinstall S, et al. Pharmacodynamics, pharmacokinetics, and safety of the oral reversible $\mathrm{P} 2 \mathrm{Y}_{12}$ antagonist AZD6140 with aspirin in patients with atherosclerosis: a double-blind comparison to clopidogrel with aspirin. Eur Heart $J$. 2006;27(9):1038-1047.

50. Wallentin L, Becker RC, Budaj A, et al. Ticagrelor versus clopidogrel in patients with acute coronary syndromes. $N$ Engl J Med. 2009;361(11):1045-1057.

51. The Medicines Company. The Medicines Company discontinues phase 3 CHAMPION clinical trial program of cangrelor [press release]. May 13, 2009. Available from: http://ir.themedicinescompany.com/phoenix. $\mathrm{zhtml} ? \mathrm{c}=122204 \& \mathrm{P}=$ irol-newsArticle $\& \mathrm{ID}=1287788 \&$ highlight $=$. Accessed November 7, 2011.

52. Leonardi S, Rao SV, Harrington RA, et al. Rationale and design of the randomized, double-blind trial testing INtraveNous and Oral administration of elinogrel, a selective and reversible P2Y(12)-receptor inhibitor, versus clopidogrel to eVAluate Tolerability and Efficacy in nonurgent Percutaneous Coronary Interventions patients (INNOVATE-PCI). Am Heart J. 2010;160(1):65-72.

53. Rao S. A randomized, double-blind, active controlled trial to evaluate intravenous and oral PRT060128 (elinogrel), a selective and reversible P2 $\mathrm{Y}_{12}$ receptor inhibitor, vs clopidogrel, as a novel antiplatelet therapy in patients undergoing non-urgent percutaneous coronary interventions (INNOVATE-PCI). Presented at the European Society of Cardiology 2010 Congress.

54. Vandendries ER, Hamilton JR, Coughlin SR, et al. Par4 is required for platelet thrombus propagation but not fibrin generation in a mouse model of thrombosis. Proc Natl Acad Sci U S A. 2007;104(1):288-292.

55. Campbell CL, Smyth S, Montalescot G, Steinhubl SR. Aspirin dose for the prevention of cardiovascular disease: a systematic review. JAMA. 2007;297(18):2018-2024.

56. García Rodríguez LA, Hernández-Díaz S, de Abajo FJ. Association between aspirin and upper gastrointestinal complications: systematic review of epidemiologic studies. Br J Clin Pharmacol. 2001;52(5): 563-571.

57. Peters RJ, Mehta SR, Fox KA, et al. Effects of aspirin dose when used alone or in combination with clopidogrel in patients with acute coronary syndromes: observations from the Clopidogrel in Unstable angina to prevent Recurrent Events (CURE) study. Circulation. 2003;108(14):1682-1687.

58. Rao SV, Jollis JG, Harrington RA, et al. Relationship of blood transfusion and clinical outcomes in patients with acute coronary syndromes. JAMA. 2004;292(13):1555-1562.

59. Rao SV, O'Grady K, Pieper KS, et al. Impact of bleeding severity on clinical outcomes among patients with acute coronary syndromes. $\mathrm{Am}$ J Cardiol. 2005;96(9):1200-1206. 
60. Angiolillo DJ, Fernandez-Ortiz A, Bernardo E, et al. Variability in individual responsiveness to clopidogrel: clinical implications, management, and future perspectives. J Am Coll Cardiol. 2007;49(14): $1505-1516$.

61. Krasopoulos G, Brister SJ, Beattie WS, Buchanan MR. Aspirin "resistance" and risk of cardiovascular morbidity: systematic review and meta-analysis. BMJ. 2008;336(7637):195-198.

62. Mason PJ, Jacobs AK, Freedman JE. Aspirin resistance and atherothrombotic disease. J Am Coll Cardiol. 2005;46(6):986-993.

63. Chen WH, Cheng X, Lee PY, et al. Aspirin resistance and adverse clinical events in patients with coronary artery disease. Am J Med. 2007;120(7):631-635.

64. Cuisset T, Frere C, Quilici J, et al. Benefit of a $600-\mathrm{mg}$ loading dose of clopidogrel on platelet reactivity and clinical outcomes in patients with non-ST-segment elevation acute coronary syndrome undergoing coronary stenting. J Am Coll Cardiol. 2006;48(7): 1339-1345.

65. Hochholzer W, Trenk D, Bestehorn HP, et al. Impact of the degree of peri-interventional platelet inhibition after loading with clopidogrel on early clinical outcome of elective coronary stent placement. J Am Coll Cardiol. 2006;48(9):1742-1750.

66. Matetzky S, Shenkman B, Guetta V, et al. Clopidogrel resistance is associated with increased risk of recurrent atherothrombotic events in patients with acute myocardial infarction. Circulation. 2004;109(25):3171-3175.

67. Collet JP, Hulot JS, Pena A, et al. Cytochrome P450 2C19 polymorphism in young patients treated with clopidogrel after myocardial infarction: a cohort study. Lancet. 2009;373(9660): 309-317.

68. Mega JL, Close SL, Wiviott SD, et al. Cytochrome P-450 polymorphisms and response to clopidogrel. N Engl J Med. 2009;360(4):354-362.

69. Simon T, Verstuyft C, Mary-Krause M, et al. Genetic determinants of response to clopidogrel and cardiovascular events. $N$ Engl J Med. 2009;360(4):363-375.

70. Gilard M, Arnaud B, Cornily JC, et al. Influence of omeprazole on the antiplatelet action of clopidogrel associated with aspirin: the randomized, double-blind OCLA (Omeprazole CLopidogrel Aspirin) study. $J$ Am Coll Cardiol. 2008;51(3):256-260.

71. Juurlink DN, Gomes T, Ko DT, et al. A population-based study of the drug interaction between proton pump inhibitors and clopidogrel. CMAJ. 2009;180(7):713-718.

72. Bhatt DL, Cryer BL, Contant CF, et al. Clopidogrel with or without omeprazole in coronary artery disease. $N$ Engl J Med. 2010;363(20): 1909-1917.

73. Chackalamannil S. Thrombin receptor (protease activated receptor-1) antagonists as potent antithrombotic agents with strong antiplatelet effects. J Med Chem. 2006;49(18):5389-5403.

74. Kogushi M, Yokohama H, Kitamura S, Hishinuma I. Effects of E5555, a protease-activated receptor-1 antagonist, on the inflammatory markers in vitro [abstract]. J Thromb Haemost. 2007;(5 Suppl 2): Abstract P-M-059.
75. Goto S, Ogawa H, Takeuchi M, et al. Double-blind, placebo-controlled phase II studies of the protease-activated receptor 1 antagonist E5555 (atopaxar) in Japanese patients with acute coronary syndrome or highrisk coronary artery disease. Eur Heart J. 2010;31(21):2601-2613.

76. O'Donoghue M. LANCELOT ACS: a prospective, randomized, doubleblind, placebo-controlled trial of a reversible PAR-1 thrombin receptor antagonist in patients with acute coronary syndromes. Presented at the 2010 TCT Congress. September 21-25, 2010. Washington, DC.

77. Chackalamannil S, Wang Y, Greenlee WJ, et al. Discovery of a novel, orally active himbacine-based thrombin receptor antagonist (SCH 530348) with potent antiplatelet activity. J Med Chem. 2008;51(11):3061-3064.

78. Becker RC, Moliterno DJ, Jennings LK, et al. Safety and tolerability of SCH 530348 in patients undergoing non-urgent percutaneous coronary intervention: a randomised, double-blind, placebo-controlled phase II study. Lancet. 2009;373(9667):919-928.

79. Kosoglou T, Reyderman L, Kasserra C, et al. Optimizing dose of the novel thrombin receptor antagonist SCH 530348 based on pharmacodynamics and pharmacokinetics in healthy subjects [abstract]. Clin Pharmacol Ther. 2008;83(Suppl 1)(S1):S55.

80. Jennings LK, Earhart A, Becker RC, et al. Thrombin receptor antagonist (TRA; SCH530348) is a selective, potent inhibitor of PAR1 activity with predictable pharmacokinetics [abstract]. Circulation. 2007;116(Suppl) (16):II 674.

81. Goto S, Yamaguchi T, Ikeda Y, et al. Phase II trial of the novel antiplatelet agent, SCH 530348, in Japanese patients with non-ST segment elevation acute coronary syndromes (NSTE ACS) [abstract]. Eur Heart J. 2008;29(Suppl):829.

82. Shinohara Y, Goto S, Shimizu K, Jensen P. A phase II safety study of novel antiplatelet agent, SCH 530348, in Japanese patients with prior ischemic stroke [abstract]. Int J Stroke. 2008;2008(Suppl 1)(3):139.

83. Committees TEaS. The Thrombin Receptor Antagonist for Clinical Event Reduction in Acute Coronary Syndrome (TRA •CER) trial: study design and rationale. Am Heart J. 2009;158:327-334.

84. Morrow DA, Scirica BM, Fox KAA, et al. Evaluation of a novel antiplatelet agent for secondary prevention in patients with a history of atherosclerotic disease: design and rationale for the ThrombinReceptor Antagonist in Secondary Prevention of Atherothrombotic Ischemic Events (TRA 2P)-TIMI 50 trial. Am Heart J. 2009;158: 335-341.

85. Schwarting M. Interim review alters phase III studies of novel antithrombotic therapy. Available from: https://www.dcri.org/news-publications/ news/2011-news-archives/interim-review-alters-phase-iii-studiesof-novel-antithrombotic-therapy?searchterm=vorapaxar. Accessed November 7, 2011.
Vascular Health and Risk Management

\section{Publish your work in this journal}

Vascular Health and Risk Management is an international, peerreviewed journal of therapeutics and risk management, focusing on concise rapid reporting of clinical studies on the processes involved in the maintenance of vascular health; the monitoring, prevention and treatment of vascular disease and its sequelae; and the involvement of

\section{Dovepress}

metabolic disorders, particularly diabetes. This journal is indexed on PubMed Central and MedLine. The manuscript management system is completely online and includes a very quick and fair peer-review system, which is all easy to use. Visit http://www.dovepress.com/ testimonials.php to read real quotes from published authors. 